\title{
A transmissão do diagnóstico e de orientações a pais de crianças com necessidades especiais: a questão da formação profissional
}

\author{
Diagnosis and guidance to parents of especial \\ needs children: a professional issue
}

\author{
Síglia Pimentel HÖHER \\ Angélica Dotto Londero WAGNER ${ }^{2}$
}

\begin{abstract}
Resumo
Quando nasce uma criança com necessidades especiais, o discurso dos profissionais da saúde, ao informar o conteúdo do diagnóstico e fornecer orientações, é de extrema importância. Trata-se de um momento significativo para os pais adquirirem capacidade de olhar para o "filho real" e não o idealizado, facilitando o processo de aceitação. O presente trabalho teve por meta apreender e analisar concepções de profissionais e estudantes da área da saúde (Medicina e Enfermagem) quanto à vivência e ao preparo para fornecerem diagnósticos e orientar pais de crianças com necessidades especiais. Utilizou-se como instrumento de coleta de dados um roteiro de entrevistas individuais, que foram transcritas e submetidas à técnica de análise de conteúdo, proposta por Bardin em 1977. As categorias obtidas na análise apontam que os profissionais da saúde entrevistados julgam que não se encontram tecnicamente preparados para informar o diagnóstico e orientar esse grupo de pais.
\end{abstract}

Palavras-chave: saúde; identidade profissional; diagnóstico; criança especial; necessidades especiais.

\begin{abstract}
When a special needy child is born, the diagnosis and guidance are extremely important so that the acceptance process of the real, not the expected child, can be facilitated. This study aimed to look into and analyze health (Medicine and Nursing) professionals and students' conceptions about their wn capabilities and experiences in providing diagnosis and guidance to parents of special needs children. Data were collected through individual interviews which were, then, submitted to a content analysis. (Bardin, 1977) The identified categories have indicated the health professionals did not feel technically prepared to offer diagnosis and guidance to those parents.
\end{abstract}

Key words: health; professional identity; diagnostic; special child; special needs.

Quando um bebê está em gestação, inúmeras modificações ocorrem na dinâmica familiar. A mulher, na figura da mãe, torna-se particularmente mais sensível, pois é ela quem sofre diretamente as modificações físicas e hormonais decorrentes da gravidez. A gestação desperta sentimentos ambíguos, dúvidas e ansiedade em relação à saúde, à vida e ao futuro do bebê. Quando a criança nasce depositam-se nela expectativas que

\section{urve}

1 Mestranda, Programa de Pós-Graduação em Psicologia do Desenvolvimento, Universidade Federal do Rio Grande do Sul. Av. Paulo Gama, 110, Campus Centro, 90040-060, Porto Alegre, RS, Brasil. Correspondência para/Correspondence to: S.P. Höher. E-mail: <sigliahoher@yahoo.com.br>

2 Professora, Curso de Psicologia, Universidade Federal de Santa Maria. Santa Maria, RS, Brasil. 
habitam o imaginário familiar, idealizadas durante os nove meses de preparo e espera (Goldenstein, 1998; Klaus, Kennell \& Klaus, 2000; Maldonado et al., 2002; Soifer, 1991).

Em todas as famílias, em maior ou menor grau, tais expectativas necessitam ser reelaboradas, pois certamente a criança frustrará, em algum aspecto, a idealização dos pais.

No entanto, para inúmeras famílias que possuem filhos com malformação ou síndrome congênita, o contato com o filho real torna-se muito mais difícil. 0 fato de ter gerado uma criança que vai exigir atenção e cuidados para além do esperado é algo temido, que pode desestruturar o casal e até mesmo levar a conflitos familiares. Isso exige dos pais grande esforço emocional para abandonar as fantasias de idealização e para vivenciar o luto do filho ideal. Esse processo é lento e causa grande sofrimento aos pais que passam por situações de negação, culpa, confusão, raiva e desespero (Buscáglia, 1997), tornando-se difícil aceitar a nova realidade.

Segundo o Censo 2000 realizado pelo Instituto Brasileiro de Geografia e Estatística (2000), 14,5\% da população brasileira possui algum tipo de deficiência, o que corresponde a 24,5 milhões de pessoas. Não há dados específicos quanto à etiologia, mas estima-se que cerca de 3,0\% dos recém-nascidos apresentem malformações congênitas, isto é, malformações presentes ao nascimento, "não conotando, nem excluindo etiologias genéticas" (Borges-Osório \& Robinson, 1993, p.151). Pesquisas realizadas por Kopp apud Bee (1996) apontam que em aproximadamente 3,0\% a 8,0\% de todos os óvulos fertilizados, o material genético contém erros porque não se dividiu corretamente. Estudos de Wahlström (1990) identificaram mais de cinqüenta tipos diferentes de anomalias cromossômicas, muitos deles bastante raros. Somente entre as causas atualmente conhecidas de retardo mental, existem 141 doenças ou transtornos com locus genético conhecido e outros 361, cujo locus ainda não foi identificado.

No Brasil, um dos maiores índices de mortalidade e de deficiência infantil se origina de causas pré-natais e perinatais (Campos, 2004). A possibilidade de nascerem crianças com algum tipo de deficiência se apresenta, desse modo, frente à crescente ocorrência de gestações de alto risco, pela idade precoce ou avançada da gestante ou por acidentes e agentes teratogênicos envolvidos, embora existam atualmente maiores possibilidades de controle com os avanços da tecnologia médica. Desses fatores decorrem a prevalência de abortos espontâneos, partos prematuros e, sobretudo, as síndromes e as doenças congênitas. Quando os pais se defrontam com o fato de ter gerado uma criança com necessidades especiais, o filho sonhado passa a não existir mais e fortes sentimentos de culpa se instalam no casal.

Nesse momento, a família procura através dos profissionais de saúde uma explicação para as causas do problema, bem como sua nomeação. Além disso, há a busca de uma resposta positiva em relação ao desenvolvimento do filho, que amenize o sofrimento e facilite o processo de aceitação. No entanto, muitas vezes o momento do diagnóstico deixa os pais confusos e sem orientação adequada, interferindo desse modo na vinculação com o bebê portador de necessidades especiais e, sobretudo, no que diz respeito às falsas expectativas, influenciando o processo de aceitação ou rejeição do filho real.

\section{O papel do profissional}

As reações dos pais ao serem informados que o filho esperado e idealizado poderá não se desenvolver normalmente por apresentar algum tipo de deficiência são variadas e dependem de muitos fatores. Porém, todos os pais necessitarão de apoio e orientação. Associada a essas reações oscilantes, normalmente, o profissional depara-se com a raiva que os pais sentem da situação, deles mesmos e freqüentemente do portador de más notícias, geralmente o médico (Ferrareto et al., 1994) ou o enfermeiro. Os mais esclarecidos, se forem informados a respeito do problema, tentarão obter mais informações através de contatos profissionais ou leituras, numa necessidade interna de encontrar alguém ou algo que negue o diagnóstico inicial e indique um prognóstico mais favorável. Outros, num processo de negação mais intenso, principalmente se a criança lhes é aparentemente normal, só tomarão uma atitude quando perceberem que algo está mesmo errado em comparação a outras crianças (Cohen, 1994). Para que essa atenção não seja tardia é preciso que os pais sejam adequadamente informados e orientados. 
No entanto, muitos profissionais da saúde não conhecem ou não consideram esses processos psicológicos, e freqüentemente os vêem como uma afronta, agressão ou ingratidão pelos serviços prestados, e, como conseqüência, percebem os pais como adversários e não companheiros no tratamento da criança (Buscáglia, 1997). Alguns parecem"esquecer"que, antes de pai e mãe de uma criança com necessidades, os pais são pessoas que não estavam preparadas para as exigências excessivas que agora se impõem, e freqüentemente esperam que com pouca ou nenhuma orientação eles enfrentem de súbito uma série de sentimentos estranhos e confusos em relação a si mesmos e ao filho (Buscáglia, 1997; Xavier, 1984). É importante perceber que os sentimentos dos pais são comuns ao de qualquer pessoa frente a uma situação desconhecida. Por outro lado, é possível que diante dessa situação difícil, o profissional da saúde também possa negar, minimizar ou intensificar a gravidade de um diagnóstico e até mesmo sentir raiva do paciente, culpando-o ou rejeitando-o (Ferrareto et al., 1994).

O que se observa é que a maioria dos profissionais não se encontra preparada para realizar esse trabalho da forma recomendada (Buscáglia, 1997; Cohen et al., 1994; Mandrá, 1998; Meiado, 1998; Mendes et al., 2002; Petean, 1995; Silva, 1988). Falta capacitação para enfrentar tal situação, o que é coerente com uma sociedade mecanicista que privilegia a eficiência e o aproveitamento de tempo. O abandono da figura do médico de família, que praticamente era um integrante dela, deu lugar para a figura do médico atual, sempre muito ocupado nos hospitais e consultórios, onde não há tempo para ouvir, explicar, assegurar e reassegurar. Mesmo quando existe tempo disponível, o médico mal preparado poderá se sentir pouco à vontade e inadequado para desempenhar um papel para o qual recebeu pouca orientação (Buscáglia, 1997).

Estudos realizados por Silva (1988) e Petean (1995) apontam a necessidade de preparar os profissionais para reconhecerem os processos psicológicos pelos quais os pais passam nesse período inicial posterior à notícia. Eles devem receber treinamento específico, visando a sua preparação acadêmica e psicológica para realizar a revelação do diagnóstico da criança e orientar a família.

Goldenstein (1998), médico pediatra e neonatologista, explicita claramente o despreparo em relação a esses aspectos dos profissionais advindos de uma formação prioritariamente técnica e traz exemplos pessoais de seu trabalho em hospitais e clínicas:

Participei de vários desses cursos e neles eu falava muito, como sempre de "técnicas" ... . Isso também haviam me ensinado na residência: como preparar o leite artificial, se fosse necessário, como preparar a comida do bebê, como incentivar amamentação, ou seja, como, como como! Não me foi ensinado nada do emocional, como lidar com isso tudo (p.20).

Foi só muito mais tarde, anos depois de formado, que aprendi que cada pessoa tinha uma história. Uma história absolutamente ímpar e original, uma história intransferível ... . O que difere uma história da outra e a individualiza é exatamente o conteúdo emocional embutido nelas ... À maioria dos médicos neonatologistas, em especial, e aos médicos clínicos em geral, esse tipo de saber não foi suficientemente ensinado e aprendido, o que dificulta muito a relação médico-paciente e gera conflitos até desnecessários (p.23).

Diante dessa falta de preparo e das dificuldades encontradas, muitos profissionais se escondem por trás de uma "distância profissional" e assim parecem não demonstrar nenhuma simpatia pelos pais que já os procuram com forte sentimento de culpa e saem supondo que o profissional acredite que realmente a falha é deles.

Essa tentativa de manter a "distância profissional" acaba levando a uma transmissão da notícia de forma destrutiva e traumatizante para os pais, além de causar a impressão de desinteresse do profissional e de que os pais, ao invés de ajudarem, apenas atrapalham, fazendo se sentirem excluídos e se excluírem do processo (Cohen et al., 1994). Nesse sentido, Ferrareto et al. (1994) colocam como um dos principais papéis do profissional que atenderá os pais de crianças com necessidades especiais, fornecer ao casal e não apenas para um dos cônjuges tanto a notícia quanto informações sobre o diagnóstico, e que se demonstre, aos poucos, a importância de a família e amigos mais próximos saberem a verdade, pois grande parte do apoio e participação efetiva virão deles. Em relação a isso, Buscáglia (1997) considera errada a atitude de alguns pais de tentarem disfarçar os fatos à família e aos parentes, sobretudo às crianças menores, no intuito de amenizar o choque, porque"é somente quando os fatos 
são disfarçados e as emoções negadas que os medos, a confusão e a impotência tomam o lugar da ação legítima" (p.86). Assim, do mesmo modo que com os pais, não se deve tirar dos familiares o direito à informação.

Telford e Sawrey (1988) apontam para uma das funções dos profissionais de ajudar os pais a compreenderem a natureza e a extensão do problema tão cedo quanto possível, tendo-se, no entanto, o cuidado de perceber o momento em que os pais estejam abertos para ouvir, respeitando seu período de sofrimento e negação. Klaus, Kennell e Klaus (2000) consideram de grande prioridade que os pais vejam sua criança após a notícia e tão logo quanto possível, pois a ansiedade pode permitir que eles imaginem algo para além ou aquém da realidade, gerando falsas expectativas. Quanto a isso, Klaus, Kennell e Klaus (2000) relataram o caso de uma paciente, cuja filha nasceu com Síndrome de Down. Ela e seu marido tiveram a oportunidade de ficar horas com o seu bebê antes de receberem o diagnóstico e, apesar de perceberem que ele tinha alguns traços diferenciados, já haviam formado um vínculo com ele antes de saberem o problema que tinha, o que facilitou lidarem com sentimentos ambíguos.

Além disso, Buscáglia (1997), Klaus, Kennell e Klaus (2000) e Telford e Sawrey (1988) enfatizam a importância de se dar uma ênfase positiva às aquisições do bebê, permitindo aos pais perceberem qualidades e não apenas anormalidades em sua criança. Faz parte de todas essas funções transmitir as informações diagnósticas de acordo com a capacidade de compreensão e aceitação dos pais, sem utilizar jargões médicos incompreensíveis que asseguram a distância entre família e profissional. A aproximação entre ambos é de extrema importância para os pais sentirem-se apoiados e à vontade para esclarecerem dúvidas, o que diminui a ansiedade e impede que fiquem sobrecarregados pelos 꼬 problemas da criança. Nesse sentido, é necessário que, além de obter informações diagnósticas claras, os pais sejam orientados quanto aos cuidados e procedimentos básicos em relação à criança e informados sobre as oportunidades educacionais, os recursos de assistência intelectual, emocional e financeira, bem como dos serviços de reabilitação disponíveis na comunidade para crianças com problemas semelhantes ao do seu filho (Buscáglia, 1997).
Assim, considerando todos esses aspectos, pode-se perceber a importância do papel dos profissionais da saúde, principalmente médicos ou enfermeiros que são os primeiros a terem contato com os pais antes, durante e após a notícia, e nos quais os pais depositam toda a confiança e esperança de cura. Suas palavras e atitudes irão influenciar provavelmente a vida de pelo menos três pessoas e estas devem ser dirigidas no sentido de ouvir, informar, compreender e educar os pais e a família a respeito do problema da criança, sobre o qual detêm maior conhecimento (Ferrareto et al., 1994).

Este trabalho teve por meta apreender e analisar concepções dos profissionais e estudantes da saúde quanto à vivência e preparo para fornecerem diagnósticos e orientar famílias com crianças portadoras de necessidades especiais.

\section{Método}

\section{Participantes}

Os participantes do estudo foram profissionais de saúde - médicos e enfermeiros - que atuam em hospitais e clínicas de Santa Maria, e estudantes dos Cursos de Medicina e Enfermagem da Universidade Federal de Santa Maria e do Curso de Enfermagem do Centro Universitário Franciscano.

Entre os profissionais envolvidos no processo de informação do diagnóstico e orientação aos pais, optou-se por limitar o estudo aos que atuam nas áreas de Medicina e Enfermagem, por serem freqüentemente esses que realizam as investigações, os diagnósticos e cuidados iniciais das crianças com necessidades especiais. Pelo mesmo motivo, foi estabelecido como critério que os médicos e enfermeiros atuassem nas áreas de Ginecologia e Obstetrícia, Pediatria ou Neonatologia, uma vez que oferecem um acesso mais claro e direto às informações de interesse da pesquisa. Do mesmo modo, os estudantes participantes deste estudo, pela possibilidade de experiência prática em estágios e em vias de conclusão de curso, deveriam estar cursando os dois últimos semestres dos seus respectivos cursos.

A fim de manter a mesma distribuição entre profissionais e estudantes e entre as áreas de Medicina e Enfermagem, buscou-se incluir no estudo quatro 
profissionais (dois médicos e dois enfermeiros) e quatro estudantes (dois acadêmicos de Medicina e dois acadêmicos de Enfermagem). Buscou-se, também, uma igual distribuição de estudantes entre as instituições de ensino superior. Tal distribuição igualitária só foi possível entre os acadêmicos de Enfermagem (um acadêmico de enfermagem da Universidade Federal de Santa Maria e um acadêmico de enfermagem do Centro Universitário Franciscano), uma vez que não existe o curso de Medicina no Centro Universitário Franciscano. Em relação aos profissionais, uma distribuição igualitária torna-se difícil pelo fato de a maioria deles atuar em mais de uma instituição hospitalar.

O contato com os profissionais e estudantes que satisfizessem os critérios estabelecidos foi realizado através da abordagem, apresentação pessoal e a explanação quanto à natureza e à finalidade do estudo, consistindo assim em uma amostra intencional, ou seja, os indivíduos são eleitos individualmente, caracterizando uma amostra pequena (Turato, 2003). De acordo com as possibilidades do interessado, marcaram-se dia e horário para efetivar sua participação. Todos os envolvidos no estudo receberam do pesquisador os esclarecimentos necessários sobre a pesquisa na forma de explicação oral pormenorizada, e, por escrito, receberam o termo de consentimento livre e esclarecido, elaborado com base na resolução MS 196/96 que versa sobre as diretrizes e normas regulamentadoras de pesquisas envolvendo seres humanos e garante o sigilo das informações coletadas. O consentimento do participante por escrito tornou-se imprescindível, constituindo-se, portanto, um dos critérios de participação do estudo.

\section{Procedimento}

Optou-se por uma abordagem qualitativa dos dados e, desse modo, foi utilizada a técnica de entrevistas individuais. A escolha dessa técnica para a coleta de dados justifica-se como mais apropriada, pois, por meio dela, o sujeito expressa pela fala e pela verbalização seus valores, crenças, representações, concepções e sentimentos em relação à temática em questão. Foi elaborado um roteiro de entrevista semiestruturada, com algumas questões norteadoras que dão conta de extrair os relatos pertinentes ao tema investigado (Anexo). Essas questões não se fecham em si mesmas, mas permitem ao entrevistado ficar livre para descrever sua vivência e ao entrevistador esclarecer as lacunas provenientes do campo de entrevista, configurado pelas variáveis que dependem da personalidade do entrevistado.

O primeiro item refere-se a dados pessoais como idade, categoria profissional e formação. A questão 9 foi elaborada para ser respondida no caso em que o participante considere que não houve preparo durante sua formação. Alguns dados referentes apenas à categoria de estudantes encontram-se no mesmo roteiro, em negrito (Anexo).

As entrevistas com profissionais e estudantes foram realizadas em um único encontro que durou, em média, 40 minutos. Todas as entrevistas foram gravadas mediante autorização e consentimento dos participantes, e as respostas transcritas na íntegra.

A partir dos relatos coletados, empregou-se a análise qualitativa dos dados por meio da técnica de análise de conteúdo proposta por Bardin (1977). Para isso, foram percorridas as etapas de pré-análise, exploração do material, tratamento dos resultados, inferência e interpretação.

Visando descrever os 'núcleos de sentido' presentes no conteúdo dos relatos dos participantes, tomaram-se como unidade de análise os temas, ou seja, as orações ou os enunciados com relação ao discurso acerca do assunto investigado "e cuja presença, ou freqüência de aparição podem significar alguma coisa para o objetivo analítico escolhido" (Bardin, 1977, p.105). Assim, as falas foram elencadas e agrupadas em categorias de análise, para, a partir de então, ser possível visualizar mais claramente as questões mais relevantes trazidas em relação ao tema. Desse modo, a categorização dos dados foi realizada a posteriori, ou seja, com base nas entrevistas realizadas. Para tanto, foram observados os critérios de recorrência do conteúdo, a intenção da mensagem, a pertinência, e a homogeneidade.

Os dados coletados foram obtidos por meio de entrevistas realizadas com um médico pediatra, um médico ginecologista e obstetra, uma enfermeira atuante na área de UTI neonatal e uma enfermeira atuante na área de enfermagem obstétrica e neonatal, 
dois estudantes de Medicina da Universidade Federal de Santa Maria, dois estudantes de Enfermagem um da Universidade Federal de Santa Maria e um do Centro Universitário Franciscano.

Visando manter o sigilo necessário, os participantes serão identificados por meio da categoria profissional ou curso de graduação (para profissionais e estudantes), seguido de um número, idade e área de atuação. Assim, a partir dos relatos dos participantes e da unidade de análise por temas, foram extraídas as seguintes categorias a serem discutidas a seguir: a falta de preparo: aprendendo com a experiência; procedimentos de abordagem; as implicações da informação; as dificuldades: quando e como informar; implicações profissionais: mudar para melhorar.

\section{Resultados}

\section{A falta de preparo}

Segundo a literatura, os profissionais da saúde não se encontram preparados para as situações de fornecer o diagnóstico para os pais de crianças com necessidades especiais. Isso se explica, a partir da fala dos entrevistados, pelo fato de que não há, desde as bases da formação em saúde, um enfoque para essa questão, que acaba ficando em segundo plano. Cabe ressaltar que tanto para os atuais acadêmicos de Medicina e Enfermagem, em sua maioria, quanto para os profissionais dessas mesmas áreas que tiveram sua formação alguns anos atrás, essa questão parece ter sido negligenciada, não havendo nenhum tipo de disciplina ou abordagem a respeito do tema:

... na minha formação não tinha nada de Psicologia, essa não era uma questão que se preocupassem, de como dar o diagnóstico, como conversar com os pais e qual a postura do profissional, é muita coisa que a gente tem que ver que isso fica de lado ... (Enfermeiro 2 - 38 anos - UTINeonatal).

Não teve preparo, assim, não teve, tem professores que procuram dar enfoque pra isso assim, mas a gente não tem uma cadeira específica pra isso, nem nada ... eu acho que assimó, a preocupação maior dos professores éque a gente faça de repente o diagnóstico, do que saber como falar prapessoa, mas que é uma coisa que falta bastante, né. Então a preocupação maior deles é a gente fazer o diagnóstico e tratar, bem objetiva que é a medicina né, objetiva até demais e, não como se fala pra pessoa (Acadêmico de Medicina 1, 22 anos).

... Não existe uma disciplina que te ensine isso, o que acontecia étu enfrentar a situação e a pessoa que estava te orientando naquele momento, seja lá o residente ou o professor, me sugerir uma conduta, que talvez fosse a certa ou a errada, mas era a conduta que ele adotava até então, então tu vai copiando a conduta dos outros né, mas não tinha uma orientação, uma base teórica pra dizer olha a conduta deve ser assim ou assado, vai seguindo o modelo dos profissionais que orientam (Médico 2 - 39 anos - Pediatra).

Entre os profissionais entrevistados, todos relataram que não receberam preparo durante a sua formação para abordar os pais e colocam que essa é uma experiência que se adquire com o exercício da profissão:

... Isso aí a gente vai com o tempo, com a tua sensatez, com teu senso de religiosidade, de humanidade, entendeu, tu vai então montando o protocolo de como dizer, como abordar né, qual é o momento, quais são as palavras que tu deve falar no diagnóstico né ... (Médico 1 - 58 anos - Ginecologista, Obstetra e Mastologista).

Étu tem um determinado suporte teórico né, eu também to sempre lendo bastante essas questões do relacionamento interpessoal, a questão das relações humanas né, isso é bastante importante, te dá uma boa base, mas ainda penso que tu aprende maiséconvivendo com as pessoas, ai sim tu acaba desenvolvendo bastante esse lado da afetividade, o lado humano né (Acadêmico de Enfermagem 2, 37 anos).

Os profissionais reconhecem a dificuldade para dar a notícia, sobretudo por se depararem com o fato de que o conhecimento que possuem não é suficiente para mudar a realidade sofrida e difícil imposta aos pais e das quais eles têm consciência:

É difícil, é muito difícil ter que dizer pros pais que o bebê não está bem, tem um prognóstico ruim, porque o profissional gostaria de chegar e dar uma notícia boa, dizer que o bebê é saudável. É uma sensação de impotência, de tu querer dar uma notícia boa enão poder mudar o que a natureza impõe, a ordem dos fatos. Éuma sensação de impotência (Enfermeiro 2 - 38 anos - UTI Neonatal). 
Édifícil, tu fica, às vezes tu mesmo fica com medo de ir lá e dá um diagnóstico, fica que meio tentando evitar, até quando tu, no início da especialização com menos experiência, tu ficava meio que negando, bah eu vou ter que ir lá, ficava arrodiando né,... claro que é sempre difícil, mas depois tu já consegue manter uma certa posição, não chorar junto porque também ali tu é um profissional né, e tu tem que esclarecer ... (Médico 2 - 39 anos - Pediatra).

Mesmo para aqueles que não passaram pela situação de fornecer o diagnóstico, esta é uma preocupação marcante:

Olha, é uma função que não é nada agradável não é?... requer um bom preparo psicológico antes disso .... Eu já tive algumas experiências, não nesse sentido, mas eu me senti, no momento assimeume sentimal, porque às vezes tu tá falando algumas coisas pra pessoas que tu não acredita, entende, no intuito de ajudar aquela pessoa ... de tu dizer assim óh, não a vida vai ser normal nah, nah, nah, naverdade não vaiser normal, a gente sabe que não vai ser, a gente sabe que vai ter momentos bens dificeis (Acadêmico de Enfermagem 2, 37 anos).

Profissionais que já passaram pela situação de informar os pais quanto ao diagnóstico do filho demonstram que a falta de preparo gera uma sensação de impotência e inadequação também frente a situações inesperadas:

... nós tivemos um bebê que nasceu com malformação, lábio leporino, então eu não sabia como falar para aquele paiquando eu fui receber o bebê efuimostrar pro pai, não é, que o bebê tinha ..., então foi assim uma situação que eunão sabiaquefazer, tinha um paifeliz porqueia receber o filho, ... e de repente eu mostro uma criança com um defeito, uma má formação assim, muito muito, assim horrivel, ... bom o homem desmaiou, o pai da criança desmaiou, quando eu vi o homem se estatelou no chão e eu não sabia o que dizer e o que fazer, foi uma situação assim muito ruim (Enfermeiro 1 - 66 anos - Enfermagem Obstétrica e Neonatal).

Compreendendo a dificuldade e a responsabilidade que recai sobre o profissional, falar o diagnóstico também aparece como uma forma de sentir-se com a missão cumprida, livrando-se de riscos pessoais e profissionais:

... eu me sinto aliviado em colocar porque eu também não posso não contar pro paciente né, eu me recordo de um caso assim de um colega meu em que o nenê tinha gastro-esquize, que é todo o abdômen aberto, com as massas viscerais pra fora do abdômen, com vinte semanas e ele tentou ficar só pra ele isso, quando viu ele pensava que ia interromper a gravidez com 38 semanas entende, mas antes disso o nenêfaleceu, ele tirou o nenê, elequasefoiprocessado pela família pornão ter contado... (Médico 1 - 58 anos - Ginecologista, Obstetra e Mastologista).

No entanto, a dificuldade em informar os pais adequadamente aparece justificada não só pela falta de preparo quanto pelas características pessoais e socioeconômicas do paciente:

Assim, écomplicado que, como eu disse a gente não tem esse preparo, tu tem que ir mais ou menos como tu falaria prum conhecido teu, tenta se colocar no lugar do paciente, mas é complicado ... essas, as mães daquitem um baixo nível socioeconômico, então às vezes elas não entendem muito bem o que tu tá querendo dizer, tu tem que ser bem clara e bem objetiva e é difícil tu fazer isso sem ser, assim, como é que eu vou te dizer, agressiva, sem serné, écomplicado (Acadêmico de Medicina 1, 22 anos).

Porém, os próprios profissionais e acadêmicos encaram a forma inadequada de colocar o diagnóstico como uma defesa contra a sensação de impotência e falta de preparo:

\section{... tem muito profissional que não se coloca no lugar do paciente por uma, por uma maneira de se proteger eu acho, por que não é todo mundo que tem uma segurança assim (Acadêmico de Medicina 2, 24 anos). \\ ... alguns médicos são muito duros e muitas vezes escondem a realidade até pela própria falta de preparo do profissional, eles usam termos que eles [os pais] não entendem (Enfermeiro 2 - 38 anos - UTI Neonatal).}

\section{Procedimentos de abordagem}

Apesar da falta de preparo mencionada, os profissionais e acadêmicos que se deparam freqüentemente com a situação de fornecer o diagnóstico e orientar explicam como procuram abordar os pais e como pensam que deva ser a postura do profissional para a tarefa de informar o diagnóstico - de uma maneira empática, apresentando a realidade e as possibilidades, sem esconder nem selar 
prognóstico, colocando-se à disposição para o que for necessário:

Eu acho que o profissional deve abordar de uma forma clara e tranqüila né, falando a realidade, as condições do bebêe não se podenegarnada. Tudo tem que ser dito por que é um direito dos pais saberem, até porque quando eles chegarem em casa com o bebê a realidade vaiestar ali, estampa-da.... falar de forma que não seja taxativa também (Enfermeiro 2 - 38 anos - UTI Neonatal).

Eu acho que não se deve colocar no momento, eu acho que já é uma situação muito dolorida já saber que tem uma lesão cerebral, tujá dizendo queéuma coisa de risco e tu dizer ainda que no futuro não vai sentar não vai caminhar, não vai falar, eu acho que é muito, muito sofrido também, e tu nem pode garantir que isso não vai acontecer, né, então eu acho que tem que te prender no momento, nesse momento ele tá assim, nesse momento o que a gente que fazer pra melhorar é isso né... não dá praselarque não vai acontecer isso, ou não vai acontecer aquilo, acho que não é de falar muito lá no futuro né, prender mais naquele momento, mas claro assim ó também tentar sempre puxar pra realidade.... não criar falsa expectativa ... (Médico 2 - 39 anos - Pediatra).

... tem que ter palavra, não pode ser aquele médico assim de táem cima de um pedestal, que ninguém pode chegar perto, só diz sim ou não, tá e não tá né, tem que abordar compalavras dóceis, lógico que botando ciência em cima disso entendeu, e dando o prognóstico, dando assistência, acho que nesse momento tu tem que dar mais assistência ainda pro paciente né. Assistência que ele vai voltar, não pode dizer 'ah, o problema não é mais comigo', não, 'a senhora volte vou lhe explicar de novo' (Médico 1 - 58 anos - Ginecologista, Obstetra e Mastologista).

Eu tenho uma idéia bem formada em relação a isso que eu acho que a gentenão tem queescondernada, eu acho que tem que fica muito claro pras mães o que tá

\section{As implicações da informação}

Os profissionais e acadêmicos entrevistados, apesar de, em sua quase totalidade, não terem obtido preparo para abordar e informar os pais desde a graduação, acreditam que a forma como o profissional usa as palavras pode provocar reações positivas ou negativas, favorecendo ou não a aceitação dos pais e a própria vinculação com a criança:

... ele pode colocar de tal forma que fique bem claro pra mãe, que ela foi uma, a culpada, queela foi incompetente de ter uma gestação completa um nenê bem formado, ou ela pode ficar com uma idéia diferente, então depende muito do que se coloca, tu vaitambém selaro prognóstico da mãe né, que a criança talvez já esteja selado, mas talvez como é que ela vai reagir a partir dali, se ela vai conseguirformar um vínculo com aquela criança, ou vai rejeitar né, então acho que depende bem de como que tu cria essa informação (Médico 2- 39 anos - Pediatra).

... esseéo diferencial porqueéo primeiro contato, vamos dizer assim, que ele vaiter com esse profissional eu penso que é o que vai direcionar, é o que vai ditar como essa pessoa vaienxergar que ele teve dalipra frente, ou como ela vai se portar com relação ao que, se ela for bem encaminhada, se ela for bem orientada,... pro relacionamento pai, mãe e filho ser bem melhor do que de repente chegar uma pessoa e simplesmente dizer assim, olha o teu filho nasceu com Sindrome de Down, a pessoa nem sabe o que que é isso às vezes ... então esse primeiro contato com o profissional é essencial (Acadêmico de Enfermagem 2, 37 anos).

Éisso que eu te falei a pessoa não se preocupa em explica nem, dá o diagnóstico de uma forma mais amena né pra que a pessoa se sinta melhor, simplesmente despeja aquilo e imagino que o paciente se sinta, a pessoa já tá numa situação que não éboa né, se sinta inferior, se sinta né, eu acredito nisso até por que as mães guardam né, o momento que foi dado o diagnóstico que elas se sentem humilhadas e estão perdidas, não sabem o que fazer e vem aquela pessoa e né, que fala daquele jeito, acredito que seja bem difícil pras mães (Acadêmico de Medicina 1, 22 anos).

Eu acho que a maneira como o médico vai dizer 'Ah, vai ser um deformado, louco' né, tem que saber usar as palavras, não isso aí é muito certo assim. O médico, a função dele é fazer com que essa criança seja bem recebida né, independente que seja Down ou qualquer coisa, qualquer má formação, síndrome, se não, nem tem nenê nessa jogada (Acadêmico de Medicina 2, 24 anos).

Apesar de se mostrarem cientes em relação à importância e às conseqüências que a forma e o ato de 
informar podem trazer para os pais, para a criança e para o vínculo entre eles, os profissionais e os futuros profissionais demonstram dificuldades em identificar as reações em relação à notícia, suas variações e o caráter natural e necessário que ela possui:

O que parece assim, que não dá pra gente saber se realmente eles não entenderam a gravidade do problema ou se, se eles tão negando né, mas o que tu nota assim éque a reação não é de choro, de espanto né, tu vê que parece que eles ficam tranqüilos normalmente assim, eu não sei se eles não conseguem entender direito o que tu tá querendo dizer ou se eles realmente não aceitaram aquilo, mas a reação não é, não é como eu vou te dizer, não é de desespero, de tristeza, uma reação parece tranqüila, a maioria pelo menos (Acadêmico de Medicina 1,22 anos).

A primeira coisa que os pais manifestam, a gestante no caso ou o marido, o paida gestante, a mãe da gestante, éprimeiro, éimaginar ... o primeiro éespanto né Mas Dr., mas não pode, o Sr. tá falando sério', mas será, mas, primeiro é uma fantasia que eles fazem né 'Mas Dr., mas não pode, ai choram, se desesperam, batem a cabeçae outros não, são sensatos, ouvem né, acreditam na gente, depende do grau, depende muito do grau de relacionamento quejá houve entre esses dois (Médico 1 - 58 anos - Ginecologista, Obstetra e Mastologista).

Neste sentido, o que torna a situação ainda mais difícil para os profissionais é o fato de os pais não acreditarem no diagnóstico e buscarem a opinião de outro profissional, soando como uma afronta:

Quando há credibilidade no profissional, ou eles imaginem interromper ... a outra situação quando não confia integralmente no médico, ah, vai vêa opinião de outro, vai noutro serviço ... faz assim uma negação, esse cara deve tá errado, eu já vi tanta coisa errada que o cara diz que tem problema e não tem, esse médico eu acho que não tá preparado, esse resultado tá errado ou então trocaram o resultado, esse filho não é meu, essa barriga não é minha, entendeu (Médico 1 - 58 anos - Ginecologista, Obstetra e Mastologista).

\section{As dificuldades: quando e como informar}

Diante da falta de preparo relatada pelos profissionais e acadêmicos entrevistados, a questão de como abordar os pais é apontada como a maior dificuldade. O que falar, como falar e em que momento falar são preocupações presentes. Desse modo, percebese mais uma vez que os profissionais acreditam na sua influência nesse momento crítico para os pais, mas não possuem preparo técnico e emocional para tais situações:

Eu acho que dificuldade maiorécomo tu vaifalar isso né, pra uma mãe que o filho dela tem um problema né, acho queéisso, essaéa minha dúvida, por que comoéque tu vaicomeçar a falar né, écomplicado, eu acho que essaé a maior dúvida assim, até que ponto o que que tu tem quefalarque aquela mãeécapazdeentender, de assimilar ou de aceitar e o que tu né, teria que deixar de fora (Acadêmico de Medicina 1, 22 anos).

De como colocar, de que maneira, eu ficava muito ansiosa, então a dificuldade de como colocar, não digamos assim, de não tornar as situações pior ainda, de que maneira eu me chegar e dizer pra esses pais e dizer que essa criança tem isso ou aquilo ou aquele outro eeu não chocar ainda mais ou de eu piorar a situação mais ainda... E eu ainda continuo com dúvidas e muitas, sempre têm (Enfermeiro 1 - 66 anos - Enfermagem Obstétrica e Neonatal).

... dúvidas de como falar, como entender melhoresselado mais psicológico dos pais, que a gente sai da formação, eu diria assim de uma forma, muito, muito crua paraestes assuntos de considerar, de como dizer, de como o profissional se portar frente a essa situação, como também com a questão da morte né, que é muito difícil (Enfermeiro 2-38 anos - UTI Neonatal).

A dúvida sempre era acho que a maneira, a melhor maneira de falar né, também naquela tentativa de pouparné, a mãeno sofrimento, então tentarfalar oque realmente era necessário, mas da melhor forma possivel, então eu nunca sabia se aquela era a melhorforma, seeu não tinha falado demais, se eu não tinha sido muito seco, né ... (Médico 2- 39 anos - Pediatra).

\section{Implicações profissionais: mudar para melhorar}

Além das implicações da forma como é dado o diagnóstico para os pais no processo de aceitação e rejeição da criança, os profissionais e acadêmicos de Medicina e Enfermagem visualizam, também, as conseqüências de uma forma inadequada para o exercício profissional. O prejuízo na relação médico-paciente, a perda da relação de confiança e a não adesão 
ao tratamento são riscos que corre o profissional mal preparado para essas situações. Nesse sentido, um preparo desde a graduação ajudaria, ainda que se considerem um fator importante a experiência profissional e a experiência de vida:

\begin{abstract}
... seria importante que durante o curso, que durante qualquer curso, principalmente no nosso que tu tá se referindo, fosse inserido ao longo da disciplina esse tipo de assunto, mais direcionado pra essas áreas mais específicas, ... porque se a pessoa necessita de um atendimento especializado tu também vai ter que ter um preparo especializado... (Acadêmico de Enfermagem 2, 37 anos).
\end{abstract}

Eu acho que sim, eu acho que sim, a gente vê, até porque, como as pessoas tratam os pacientes hoje em dia, uns tratam de uma forma, outros tratam de outra, até porque talvez eu acho que a parte da relação médico-paciente não é tão, tão insistida pelos cursos, ou os alunos não aproveitam ... não exploram mais não introjetam ela, de qualé a função dela né... (Médico 2 - 39 anos - Pediatra).

Desse modo, consideram que algumas questões em relação à formação do médico e do enfermeiro poderiam ser modificadas ou acrescentadas. Dentro da visão de que a experiência e os princípios pessoais falam mais alto do que um possível preparo na formação, este aparece como necessário para fornecer diretrizes aos profissionais que se deparam com essas situações, de forma que possa ser um suporte técnico e emocional, além de uma tentativa de sensibilizar os profissionais menos sensíveis, tornando este momento difícil por definição, menos frustante e angustiante para os pais.

Eu acho que deveria de ter sim, um curso dentro da medicina, dentro da enfermagem, ter um acompanhamento de psicologia, uma disciplina, eu concordo uma disciplina porque aí eu acho que a gente vaihumanizar. Seouvetanto essa palavra humanização, isso aímeu Deus do céu, todo mundo alarda, mas a gente não tem preparo, apesar que isso tu tem o curso e não adianta né, isso é muito do teu lado pessoal... (Enfermeiro 1 - 66 anos - Enfer-magem Obstétrica e Neonatal).

... eu acho que dentro de uma disciplina dessas, esse tipo de experiência deveria ser abordado, e dado algumas diretrizes, não que seja uma receita de bolo né, de como que a pessoa vai agir naquele dia, vai depender muito da experiência que ela passou também na vida né... eu acho que vai pesar muita coisa, mas eu acho que algumas, algumas sugestões poderiam ser dadas né de como conduzir nessa situação né (Médico 2 - 39 anos-Pediatra).

\section{Considerações Finais}

A partir deste estudo podemos levantar algumas questões significativas que se referem a esse importante tema. Ao longo do trabalho, tanto pela revisão de literatura quanto pelo contato com profissionais e estudantes durante as entrevistas, pode-se perceber que esse tema surge como um aspecto negligenciado na formação acadêmica dos profissionais, que se colocam como despreparados frente às situações diagnósticas dessa natureza.

Foi possível perceber que as dificuldades mencionadas pelos profissionais para abordar os pais encontram-se no âmbito pessoal e técnico, como informar o que foi constatado sobre as condições de saúde e integridade física da criança e reconhecer as reações dos pais como naturais e esperadas, acima de tudo. Reconhecem que o perfil de cada profissional, sua experiência pessoal, familiar e profissional contribuem no delineamento de uma postura adequada para informar o diagnóstico, juntamente com o preparo desde a base da formação acadêmica, que se torna necessário para que algumas noções e diretrizes sejam dadas, além de possibilitar uma visão humanitária e não apenas técnica, na tentativa de sensibilizar os profissionais, cuja tendência pessoal prioriza outros aspectos.

Desse modo, ao apontar mudanças julgadas como necessárias para a melhoria dos serviços prestados aos pais nesse momento difícil, os profissionais demonstram valorizar o modo de informar, entendendo sua importância não só para a saúde física, mas emocional, e para a construção do vínculo entre os pais e a criança, a partir de um processo de aceitação facilitado ou prejudicado pela forma com que o diagnóstico é colocado. O investimento nesse aspecto negligenciado desde a graduação tornaria o momento menos angustiante não só para os pais como para os profissionais, contribuindo assim para a qualidade do 
serviço profissional prestado e da relação médico-paciente, ambas também necessárias para adesão do paciente ao tratamento, em qualquer caso.

No entanto, essa questão de preparar os profissionais desde a graduação continua sendo considerada menos importante do que a técnica médica. Dos profissionais entrevistados, cuja formação se deu há alguns anos, todos relatam que não tiveram preparo durante a graduação para comunicar o diagnóstico aos pais de crianças com necessidades especiais. Já em relação aos acadêmicos, dois relataram que estão recebendo preparo, porém muito vago ou precário e apontam melhorias nesse sentido, como a criação de disciplinas de Psicologia sobre o assunto, suporte técnico, emocional e humanização da saúde. Diante disso, é possível perceber o interesse e a preocupação dos profissionais e estudantes em adequar cada vez mais a forma com que informam o diagnóstico a partir de suas experiências profissionais, porém apontam que um preparo mais adequado facilitaria esse processo.

A referência à questão da humanização dos cursos de saúde aparece em alguns momentos nos relatos coletados como algo necessário, mas que precisa sair da teoria e começar a ser mais insistida e discutida nos bancos escolares, além de ser utilizada na prática profissional. É importante destacar que a notícia a ser dada inevitavelmente frustrará os pais e trará à tona mecanismos de reação psicológica inicial, tais como o choque e a negação, que podem passar pelo sentimento de raiva em relação ao portador de más notícias, independentemente de como o profissional informa. No entanto, é possível perceber que há formas mais adequadas de os pais serem informados, que evitam a intensificação do sofrimento.

Reconhecendo-se as limitações do trabalho, essas evidências apontam, portanto, para a necessidade de melhorar a formação dos profissionais para que atuem nessa área do diagnóstico precoce de maneira adequada e possam informar e orientar, sem gerar preconceitos ou reforçar esteriótipos sobre a condição da criança, o que pode influenciar negativamente a interação do indivíduo com seus familiares e posteriormente com a sociedade. Assim, poderão estar correspondendo melhor às necessidades apresentadas pelos pais neste momento de intensa dúvida e angústia, proporcionando-Ihes, talvez, um apoio de maior qualidade, tornando-se continentes aos seus sentimentos e reações durante uma etapa tão inesperada de suas vidas.

\section{Referências}

Bardin, L. (1977). Análise de conteúdo. Lisboa: Edições 70.

Bee, H. (1996). A criança em desenvolvimento. São Paulo: Haper e Row do Brasil.

Borges-Osòrio, M. R., \& Robinson, W. M. (1993). Genética humana. Porto Alegre: Artes Médicas.

Buscáglia, L. (1997). Os deficientes e seus pais: um desafio ao aconselhamento (3.ed.). Rio de Janeiro: Record.

Campos, M. B. Causas das deficiências. Acesso em setembro 28, 2004, disponível em http://pentaufrgs.br/causade deficiencias

Cohen, M. D., Ardore, M., Honda, R. A., Samejina, A., Sarruf, M. C., \& Silva, B. P. A. (1994). Ações integradas na reabilitação de crianças portadoras da Síndrome de Down. In A. M. Kudo, E. Marcondes, L. Lins, L. T. Moriyama, M. L. L. G. Guimarães, R. C. T. P. Juliani, \& S. A. Pierri (Orgs.), Fisioterapia, Fonoaudiologia e Terapia Ocupacional em Pediatria. Monografias Médicas (2.ed., v.2, pp.266-281). São Paulo: Sarvier.

Ferrareto, I., Ferreira, A., Ignácio, A., Prado, A. E. O., Pinto, M. C. F., Moura, M. J., \& Rizzo, A. M. P. P. (1994). Ações integradas na reabilitação de crianças portadoras de paralisia cerebral. In A. M. Kudo, E. Marcondes, L. Lins, L. T. Moriyama, M. L. L. G. Guimarães, R. C. T. P. Juliani \& S. A. Pierri (Orgs.), Fisioterapia, Fonoaudiologia e Terapia Ocupacional em Pediatria. Monografias Médicas (2.ed., pp.283-290). São Paulo: Sarvier.

Goldenstein, E. (1998). Sua majestade o bebê: conversando com papai e mamãe. São Paulo: Casa do Psicólogo.

Instituto Brasileiro de Geografia e Estatística. Censo 2000. Acesso em junho 27, 2004, disponível em: http:// www.ibge.org.br

Klaus, K., Kennel, J., \& Klaus, P. (2000). Vínculo. Porto Alegre: Artmed.

Maldonado, M. T., Dickstein, J., Nahoum, J. C. (2002). Nós estamos grávidos (12.ed.). São Paulo: Saraiva.

Mandrá, P. P. (1998). Análise de informações captadas por mês sobre o desenvolvimento da linguagem de seus filhos com síndrome de down. Dissertação de mestrado nãopublicada, Universidade Federal de São Carlos.

Meiado, A. C. (1998). O retrato da exclusão: um estudo de caso sobre a deficiência mental severa no ambiente familiar. Dissertação de mestrado não-publicada, Universidade Federal de São Carlos.

Mendes, E. G., Nunes, L. R. O. P., Ferreira, J. R. (2002). Diagnóstico e caracterização de indivíduos com 
necessidades educacionais especiais: produção científica nacional entre 1981 e 1998. Temas em Psicologia da SBP, 10 (1), 11-25.

Petean, E. B. L. (1995). Avaliação qualitativa dos aspectos psicológicos do aconselhamento genético através do estudo prospectivo do atendimento das famílias. Tese de doutorado não-publicada, Faculdade de Ciências Médicas, Universidade Estadual de Campinas.

Silva, S. F. (1988). Experiências e necessidades de mães após o diagnóstico de deficiência mental do filho. Dissertação de mestrado não-publicada, Universidade Federal de São Carlos.

Soifer, R. (1991). Psicologia da gravidez, parto e puerpério (5.ed.). Porto Alegre: Artes Medicas.
Telford, C. W., \& Sawrey, J. M. (1988). O indivíduo excepcional (5.ed.). Rio de Janeiro: Livros Técnicos e Científicos Editora.

Turato, E. R. (2003). Tratado demetodologia Clínico-Qualitativa. Petrópolis: Vozes.

Wahlström, J. (1990). Gene map of mental retardation. Journal of Mental Deficiency Research, 34, 11-27. Acesso em julho 26, 2004, disponível em http://www.capes.org.br

Xavier, M. A. V. (1984). O outro lado do arco-íris: meu filho Ricardo (2.ed.) São Paulo: Diniz.

Recebido em: 28/6/2005

Versão final reapresentada em: 15/12/2005

Aprovado em: 05/1/2006 


\section{ROTEIRO DE ENTREVISTA SEMI-ESTRUTURADA PARA PROFISSIONAIS E ESTUDANTES}

\section{Roteiro de entrevista: profissionais e estudantes}

1. Dados Pessoais

Idade:

Sexo:
( ) Profissional
( ) Estudante
Semestre:
( ) Medicina
( ) Enfermagem

Especialidade/Residência em:

Formação:

\begin{tabular}{ll} 
( ) Graduação & Ano: \\
( ) Pós-Graduação & Instituição: \\
\hline
\end{tabular}
Qual?

2. Você considera que teve (ou está tendo) preparo durante a graduação para as situações diagnósticas?
( ) $\operatorname{sim}$
( ) Não

Por quê?

3. Você já passou pela experiência de fornecer o diagnóstico e/ou orientações para pais de crianças com necessidades especiais?

( ) $\operatorname{sim}$

( ) Não

\section{Caso Sim}

4. Como se sentiu nessa situação?

5. Como procurou abordar o assunto?

6. Como percebeu a reação dos pais?

7. Houve dúvidas e dificuldades? Quais?

\section{Caso Não:}

4. Como você imagina que seria fornecer o diagnóstico e as orientações para pais de crianças com necessidades especiais?

5. Como você o faria?

6. Diante dessa ação, como você imagina que seria a reação dos pais?

7. E a sua?

8. O que você acha que deveria melhorar em relação ao preparo dos profissionais da saúde para situações diagnósticas?

\section{Caso considerado em que não houve ou não há preparo:}

9. Você acha que a falta de preparo para dar diagnósticos, esclarecimentos e orientações durante a formação compromete (ou pode comprometer) o exercício profissional?

10. Tem mais alguma coisa que você gostaria de acrescentar a respeito desse assunto? 
